In Ageing \& Society, 27, 2, 285-305

\title{
Clothing, Age and the Body: A Critical Review
}

\author{
Julia Twigg ${ }^{1}$
}

\begin{abstract}
Clothes are central to the ways older bodies are experienced, presented and understood within culture, so that dress forms a significant, though neglected, element in the constitution and experience of old age. Drawing on a range of secondary literature, the article traces how clothing intersects with three key debates in social gerontology: concerning the body, identity and agency. It examines the part played by clothing in the expression of social difference, exploring the role of age ordering in determining the dress choices of older people, and its enforcement through moral discourses that discipline the bodies of older people. Dress is, however, also an arena for the expression of identity and exercise of agency, and the article discusses how far older people are able to use clothing to resist or redefine the dominant meanings of age. Lastly it addresses questions of the changing cultural location of older people, and the role of consumer culture in the production of Third Age identities.
\end{abstract}

Key words: body, identity, agency, resistance, dress, clothing, consumption

\section{Introduction}

Clothes mediate between the naked body and the social world, the self and society, presenting a means whereby social expectations in relation to age act upon and are made manifest in the body. They thus play a potentially important role in our understanding of the cultural processes of ageing. Clothing and age has, however, been a neglected subject: there is little empirical or theoretical work that addresses the topic directly. I will argue in this article, however, that clothing and dress engage with three of the key debates current in social gerontology - those relating to the body,

\footnotetext{
${ }^{1}$ School of Social Policy, Sociology and Social Research, University of Kent, Canterbury, Kent, UK
} 
identity and agency - and that clothes provide an arena in which such debates can be pursued.

The body is central to the experience of ageing, though the extent of its relevance has been subject to contestation particularly from cultural critics who have sought to emphasis the ways in which aged bodies are the product of the cultural discourses that constitute them and endow them with specific meanings. Clothing is significant to these debates because it mediates the relationship between the body and the social world, forming the vestimentary envelope that contains and makes manifest the body, offering a means whereby it is experienced, presented and given meaning in particular social contexts. We conceive of the body through the medium of dress. How clothing operates in relation to age is thus significant for our understanding of how cultural expectations concerning age act upon and present the body.

Questions of the body and age are also linked to debates about the nature of identity in high- or postmodernity. If identities have indeed altered, as postmodern critics claim, becoming more fluid and fragmented, more closely linked to the culture of consumption, what is the impact of this on the experience of age? In particular, how far has the emergence of the new social space of the Third Age, with its roots in consumer culture, affected the ways identity in age is experienced; and what role does a factor of consumption like clothing play in this? Proponents of Third Age identities argue that these are constructed in terms of the extension of mainstream consumer culture to the category of the aged. Such approaches suggest that the old pattern of age ordering in dress will have given way to a new fluidity, in which garments are chosen without consideration of, or in countervalance to, considerations of age and its cultural associations. These assertions have, however, been challenged. Identities may not be as fluid, nor as optional as is claimed, and voluntarism in relation to both identity and dress not as great as postmodern critics - themselves influenced by the discourses of consumer society - assert. The field of ageing, the body and dress provides one arena in which such questions can be explored.

Questions of choice and identity also raise issues of agency. Clothing in consumer culture is predominately articulated in terms of choice and the exercise of agency, though these choices take place in a cultural and economic context that constrains and 
shapes them closely. How free are older people to exercise agency in dress? In particular how far are they able to use clothing to resist, reinterpret or redefine dominant messages about age? Clothing, particularly for older women, is often embedded in moral prescriptions that act to police their bodies and entrench the micro-social order. How far are they able to offer resistance to these meanings, and how does such resistance relate to the tension between strategies of age-denial or ageaffirmation? Is it possible to pursue an ideal of agelessness, and what might this mean in the context of bodily change?

The subject of clothing and the body thus raises a number of questions in relation to the meaning and experience of ageing in high- or post-modernity. Before discussing these, however, we need to address why clothing and age has been a neglected subject academically, and to clarify two points concerning the scope of the subject.

\section{The neglect of clothing and age}

One reason for the neglect lies in the nature of the academic analysis of fashion and its predominant location in the areas of art, art history and cultural studies (Hollander 1978, Craik 1994, Ribiero 1995, 2002, 2005, Breward 2000, MacDonald et al 2003). This has given a specific flavour to the analysis. Fashion studies tend to focus on the elite fashion of haute couture or of style leaders, or on the analysis of sub-cultural groups like street tribes (Polhemus 1994, Steele 1997). The fashion literature, like the fashion industry, is concerned with spectacle, display and creativity; it celebrates the edgy, the fashionable, the erotic, the transgressive (Evans 2003). Older people have little place in such a literature, indeed they are consciously excluded from it. Reviewing academic writing on fashion revealed almost nothing on age or on the clothing choices of older people. At the heart of the issue is the assumption that fashion is all about sexuality; and older people are assumed - certainly in the eyes of the young - to be beyond sex. Their clothing choices are, therefore, of no interest or relevance to studies of fashion, and indeed to include them would, in the eyes of many, degrade the subject matter.

The topic of clothing and age has been neglected from the perspective of social gerontology also. This is partly because of the bias in the discipline towards problematic old age and the challenges this presents at a societal level. This has 
produced an emphasis on the resources of the public or semi-public sector rather than the world of private consumption, and on the themes of need, functioning and deficiency rather than expressivity, identity and choice. More recently, however, this emphasis has begun to change with the emergence of cultural gerontology (Cole 1992, Andersson 2002, Katz 2005) and of new and more plural understandings of the meanings and significance of ageing influenced by postmodernism and the cultural turn. The emergence of the Third Age as a new social space, broadly encompassing late middle age and associated with prosperity and leisure, has reinforced these trends. As Gilleard and Higgs (2000) argue, later years need now to be seen as much in terms of consumption, social engagement and personal development, as loss, frailty and decline. Clothing is part of this.

The third reason for the neglect of clothing and fashion relates to the widespread sense within the academy and beyond that these are trivial subjects not meriting serious analysis. As Tseelon (2000) comments, to engage in research on dress is to place oneself on the fringes of academic respectability. This has been particularly true within mainstream sociology which inherited many of the prejudices against fashion found in earlier moralistic writings. From its inception sociology, with its bias towards rationality and the masculine-defined worlds of work and the public sphere, tended to regard subjects like fashion as lightweight and superficial. Their association with the feminine further undermined their status; and as Entwistle (2000) notes there are parallels here with the initial disregard within sociology of topics like the body and emotion. These perceptions were reinforced by the views of feminists of the Second Wave who associated fashion with discredited and oppressive forms of femininity (Friedan 1963, Greer 1971, Daly 1979, Jeffries 2005). Fashion distorted the natural body through subordinating practices like high heels, corsets and objectifying fashions that reduced women to objects of a sexualising gaze, rendering them unable to act effectively in the world. It diverted women's energies into trivial questions of appearance; and reinforced negative stereotypes of women as everchanging, inconstant, narcissistic. Under the impact of postmodernism, however, there has been a revaluation of fashion within feminist writing as part of the wider development of work on the body. As Wilson (1985) argued, the presentation and adornment of the body through dress is an inescapable fact of social life. There is no natural - or unnatural - way to dress, any more than there is a natural body. And 
indeed for many women, dress presents a significant source of aesthetic pleasure, a

valued opportunity for self-fashioning and personal reflexivity. Postmodern feminism has thus recovered dress as an area of legitimate interest, and in doing so has challenged some of the implicit denigration of women's culture that has traditionally been bound up in the condemnation of dress (Tseelon 1995).

\section{Gender: men too?}

In this article I will largely address questions of dress and age in relation to older women. This because the field of fashion and dress is culturally constituted as a feminised one, its discourses predominantly embodied in the lives of women. As a result women in contemporary culture are more engaged with fashion at every level: spending more money on clothes, more time shopping, more attention to reading about the topic; though men are, of course, significantly involved in the higher levels of the fashion industry. Clothing for men since the nineteenth century and Flugel's (1930) Great Renunciation in which men abandoned the richly coloured and decorated clothing of earlier centuries, has been contained within a narrow range of reference, one more closely concerned with correctness and micro-issues of style, and dominated by a subdued palette. Pre-occupation with dress in men is often condemned as effeminate, associating men with negatively perceived female qualities of vanity and narcissism. In dominant constructions of masculinity, it is dangerous territory; and men are often wary of the subject. In more recent years, some of this condemnation has eased, at least among younger men, with the impact of consumer society and the emergence of new masculine subjectivities such as metrosexual man. It remains the case however that men tend to be less involved than women in questions of fashion, and this fact is reflected in the literature which is heavily biased towards women. As a result, this article, though it aims to address both genders, remains weighted towards the experiences of older women.

\section{Clothing not fashion}

The article addresses clothing not fashion. Most writing on dress is rooted in the analysis of fashion, both in the sense of elite, design sources and of the changing cycle of fashion, which is seen as fundamental to how fashion and the Fashion System (Fine and Leopold 1993), understood as the constellation of production, retail and media influences that together shape clothing choices, works. As we shall see, the 
historical emergence of this dynamic of change is linked to the rise of modernity. My concern in this article, however, is not so much with fashion as dress. By this I mean a focus on clothing as an everyday bodily practice in which a variety of influences including those of the fashion system - come into play. Such a focus is particularly relevant in older people who are, by and large, ignored by the fashion industry. Concentrating on clothing allows us to acknowledge the ways in which these are groups who are also dressed; how they too wear clothes and make clothing choices. In particular it allows us to extend the theoretical analysis to people like older men who are not normally encompassed within such studies, but for whom questions of clothing and dress are still relevant.

\section{Clothing and the body}

In recent years the body has been the subject of an extensive literature across the arts and social sciences. Initially, this work shared some of the gerontophobia that we noted earlier in relation to fashion studies; there was a tendency to avoid the subject of ageing bodies, and to focus on younger, sexier topics. Social gerontology was similarly reluctant to address the ageing body, preferring to emphasise social structural factors in the constitution of age; though more recently there has been a greater willingness to engage with questions of the body and embodiment (Katz 1996, Oberg 1996, , Gulette 1997, 1999, Tulle-Winton 1999, 2000, Woodward 1999, Gilleard and Higgs 2000, Wahidin 2002, Twigg 2004, Dumas et al 2005).

Early work on the body, particularly that influenced by post-structuralism, sometimes adopted extreme versions of social constructionism that appeared at times to deny the existence of the physical body. The body disappeared in a cloud of language and discourse. Since then, particularly under the impact of critiques launched from the perspectives of medical sociology, the study of chronic illness and pain (Bury 1982, 1991, Leder 1990, Bendelow 1993, Lawton 2000), and work broadly influenced by Critical Realism (Williams 1999) and from a desire to transcend the implicit dualism of such accounts (Shilling 1993, 2005, Crossley 2001) and to recover a focus on embodiment associated with the work of Merleau-Ponty (1962), there has been a return to a sense of the body as a concrete reality, as a generator as well as receptor of meanings. As a result it is possible now to acknowledge the physical reality of the body without appearing to abandon the subject to biological reductionism. 
These debates are significant here because we need to understand clothing and ageing in terms of the interplay of cultural and biological factors. Most of what I will discuss in this article relates to social and cultural patterns: to how clothes operate within a system of age ordering; to how we use clothes to display, underwrite and express social and cultural meanings; and how these are challenged, subverted and subtly altered by the behaviour and choices of individuals, albeit always operating within a social context. But the subject of clothing and age needs to be related to physiological factors also. The body as it ages, changes (Smathers and Horridge 1978, Goldsberry et al 1996 ); and these changes need to be incorporated into decisions about dress at an individual level. Styles that once fitted or 'suited' - the category is, of course, cultural - may no longer do so as the body ages. The transition to ageing is indeed a culturally negotiated one, but it is one in which the body plays a direct and immediate part. At an individual level, people come to recognize their own ageing through changes in bodily appearance, and these changes are reflected, or resisted, in clothing choices. In the Third Age, most of these changes are ones of appearance rather than function, relating to factors like muscle tone, skin quality, body shrinkage and thickening. But the transition to the Fourth Age can impose more radical adjustments, as individuals accommodate changes in relation to, for example, mastectomy or colostomy, troubles with continence, difficulties with feet and walking. All these present new demands in relation to dress, but ones that still require to be negotiated within cultural and aesthetic structures. They can mean, however, that it becomes increasingly difficult to remain part of mainstream culture in relation to clothes. The interplay of the body and clothing, thus, presents opportunities to explore the ways in which ageing is both a physiological and cultural phenomenon, and the complex interplay of these factors in the lives of older people.

\section{Identity, clothing and age}

Clothes are expressions of identity, one of the perennial means whereby we signal to the social world who and what we are, part of our repertoire of social technology, a means whereby ideas of identity are grounded in the visual (Tseelon 1995). But this expressivity operates within a cultural context that assigns distinctive meanings to social forms. They are part of how cultural expectations are translated into specific requirements in relation to appearance, forming a means whereby identity in age is 
constituted at the level of individual bodies. We can explore this through the literature on clothing and social difference.

\section{Clothing and social difference}

Clothes play a vital though often unacknowledged role in the constitution of social difference (Breward 2000). We can see this clearly in relation to gender. Fashion, as Entwhistle (2000) notes, is obsessed with gender, with the complex interplay between sexed bodies and gendered modes of dress. Dress indeed provides a particularly clear example of Butler's $(1990,1993)$ concept of the performativity of gender. Clothes act to define and naturalize gender, rendering what is constituted and performed as if it were natural and self-evident. They make gender visible and obvious, reproducing it as a form of body style. Butler chose to focus on clothes, and in particular drag, precisely because of their capacity to disturb assumptions commonly made about the interlinkages between sexed bodies, gendered performance and sexual identity.

Dress is also significant in relation to other forms of social difference, for example sexuality. There is now a considerable literature on gay and lesbian fashion and its role in articulating the emergence of distinctive and visible sub-groups around the expression of sexuality particularly in the twentieth century (Rolley 1993, Holliday 2001). Similar work has explored the ways in which 'race' and ethnicity interact with norms of fashion, underpinning distinctively ethnic forms of dress, as well as the complex interactions between modes and styles associated with migrant cultures and their variation, expression and counter expression in the countries of adoption and subsequent descent (Khan 1993). Clothing can thus play an important part in signaling, or erasing, aspects of identity.

The connection between clothing and class has been particularly emphasised within sociology; indeed as we shall see later, social class has been central to both the analysis of fashion and the explanation of its historical emergence. To this day class remains a significant determinant of dress; we read social class position off from clothing style. Clothing here reflects a variety of influences - partly economic, but also partly sub-cultural, reflecting distinctive forms of dress that are associated with class-defined groupings. 
Much of the work on clothing and social difference is located within sub-cultural analyses in which the focus is on the use of clothes and body styling as a means of marking out the boundaries of the group, stabilising identity and registering belonging. These analyses tend, however, to be strongly focused on youth culture and transgressive, counter-cultural styles. Sub-group analysis is rarely deployed in relation to social groups who might be regarded as 'conservative' or 'traditional' in their cultural location, even where these may be socially marginalised and to that extent 'counter cultural' in their values. It is not particularly helpful, therefore, to try and think of older people and their dress in sub-cultural terms. A better way to present the issue is in terms of age ordering.

\section{The age ordering of clothes}

The age ordering of dress is something that operates through the life course. It is perhaps most evident in relation to childhood, where distinctive age-related forms of dress are common. The degree to which childhood is marked out in this way has varied historically; and the popularisation of distinctive forms of dress for children is associated in particular with the emergence of the modern culture of childhood rooted in Romanticism. More recently children's clothes have become less, rather than more, distinctive, approaching nearer to adult modes, certainly nearer in the degree to which they reflect the cycle of adult fashion as part of the extension to children of consumption society. When we turn to later years, however, the categorisations become less clear. There are not the same clues in relation to size that there are with children's clothes. Indeed from one perspective there are no clothes for older people as such, simply a range of clothing from which different individuals make choices according to a variety of lifestyle, income and aesthetic preferences. And yet at the same time, there are clearly observable differences in dress that relate to age. There is no single point in the life course or in terms of chronological age when these differences emerge: people adopt 'older' styles at varied points in their lives. The characterisation of such older styles is also somewhat blurred. However they clearly exist, and are recognisable to individuals within the culture (in this case, the culture of western societies in the early twenty-first century).

If such age ordering exists, what are its concrete manifestations? I want here to draw on the writing of Alison Lurie and her Language of Clothes (1992) in which she 
advances interpretations of the meanings of a variety of different forms of dress. Lurie writes as a novelist with an understanding of the contingent nature of such meanings; and it is important in reviewing them to recognize that they are fluid and contextual, rooted in particular historical and social configurations. In general, attempts by fashion theorists to establish enduring interpretations of forms of dress have not proved successful, the very plurality and cultural plasticity of dress resisting such efforts. Indeed some argue that clothing, and certainly fashion, follows its own aesthetic dynamic that means it cannot be fully reduced to social and cultural interpretations.

Lurie (1992) makes three suggestions in relation to clothes and older people. The first concerns the tendency for clothes for older people to be longer and to some degree more shapeless than for the young; and she points to the history of the long robe and its association over many centuries with older men particularly in a dignified context. This is a garment that is no longer available to men - except in its vestigial form of the judge's robe or academic gown - but it finds some echo in women's clothes, where the general rule of 'Longer Equals Older' (p51) applies, certainly to skirt lengths. Younger women by contrast are free to choose from the full range of lengths. The shift towards looser cut, with less definition at the waist, is also characteristic of older women's dress, though here there is an interaction with bodily change (Goldsberry et al 1996).

Lurie also suggests connections between age and colour. Within the dominant colour system of the modern West, older women are associated with muted, dull, soft colours like beige, grey, lilac, navy. Iltanen's study (2005) in which designers were asked to select garments appropriate for women in their fifties and sixties similarly found that the ones chosen were predominantly dark or in muted tones. Black as a colour, although connected with age in the past, is now more ambivalently located, since it contains the dual meanings of mourning and thus widowhood, but also of drama and display - the dangerous black of fashion and sexuality (Harvey 1995). Muted, quiet colours themselves have multiple referents, and in the last two decades have become associated for women with professional dress and the shift in women's office clothes towards the sexually neutral work ideal of men's suitings. But worn by older women 
these pale, grey, beige non-colours suggest social retirement, a withdrawn and sidelined status.

The adoption of dull, neutral colours in age relates to the more general practice of 'toning down', in which there is a retreat from eye-catching styles or overly sexual display. These neutral colours also draw on counter meanings, in that they are consciously not bright, attention grabbing colours like yellow or red. Indeed such colours, particularly red, are often presented as 'unflattering' or unsuitable for older women, suggesting as they do an overt sexuality, a brazen, vivid quality that is well conveyed by the word scarlet, with its multiple moral and social referents. We can hear echoes of this colour system in Jenny Joseph's poem Warning that has achieved remarkable popularity, being voted the one of the nation's favourite poems in BBC poll in 1996. Its success is less to do with its quality as poetry than its resonance with the lives and feelings of many women. The poem describes everyday acts of defiance and resistance, a number of which relate to dress, notable among which is the wearing of purple, which has come to represent the poem. Purple as Lurie (1992) notes is an ambivalent colour, associated with royalty and gorgeousness, but also vulgarity and coarseness. And the poem in emphasising this colour encapsulates the resistance to demands to tone down behaviour and dress, and to become grey and invisible.

The third connection made by Lurie is rather different, and in some ways reverses the earlier meanings of sobriety and self-effacement. This concerns the return to childishness in the dress of some older people, particularly in America; and she points to the bright colours and bold patterns normally associated with toddlers adopted by some older Americans living in resorts or retirement villages. These clothes draw heavily on the repertoire of leisure dress, and part of their meaning is precisely to be at play, no longer constrained by the norms of business dress, with its emphasis on the sober, dark and structured. These sports clothes allow for body movement, and with it spread. Elastic waistbands and Spandex fabrics accommodate changes, but in ways that maintain an integration with mainstream younger clothing through the metaphor of sport. But they are also clothes that signal a return to the comfort and ease of babyhood; there is something asexual about the toddler-like shapes and colours. By the same token they are also easy to clean, again pointing to the linkages between the bodies of old people and of babies. 
Before going on to ask how rigid or extensive this age ordering is, and how far there is evidence of individual resistance and change, we need to explore the linkages between clothing and morality, for it is through the operation of moral discourses around dress that age ordering is maintained.

\section{The moral ordering of dress: policing the aged body}

One of the recurring features of writing on dress has been the moral language within which it is encoded. Dress is frequently spoken of in moral terms: as good, bad, faultless, correct, vulgar, tarty, cheap. Like food it attracts to it language that reaches beyond the phenomena being described. There is a powerful moral charge to this - an overdetermined quality that draws strength from the ways in which both food and clothing are cultural fields concerned with the body, its expression and control. Dress is thus part of a set of wider processes around the disciplining of the body, constraining and enabling its expression, making it subject to discourses of morality.

There are two ways in which we can observe this moral ordering operating differentially and distinctively in relation to older people. The first concerns the significance attached to lapses of dress. In general being correctly dressed is an element of engaging successfully with the social world. Entwhistle (2000) notes how unease and anxiety attach to failing to meet the standards required by the moral order of the social space; and individuals feel vulnerable and embarrassed if their dress lets them down, through laddered tights, drooping hems, and other failures of appearance. But in relation to older people these strictures operate in a harsher way, pointing to new and threatening meanings. Lapses of dress like stains, visible food marks, gaping buttons, are not just offenses against performance norms of the social space, but signals of a larger social and moral decline that may threaten their capacity to remain part of mainstream society. In the context of old age, there is no longer the possibility of Herrick's 'sweet disorder of the dress': the erotic evaporates, to be replaced by the untidy and derelict. Older people thus find themselves caught within an altogether harsher moral climate in relation to dress - harsher at least if they do not want to accept the reduced and changed identities that such sartorial failings signal - one that disciplines and judges their bodies more strictly than those of younger people. 
The second sense in which dress operates to police the bodies of older people relates to sexuality. Dress plays a central part in the expression of sexuality. Indeed from the perspective of mainstream fashion theory, sexuality is the key to fashion; and we noted earlier how the exclusion of older women from fashion discourse was in large part related to assumptions about sexuality. For many older women one of the most powerful discursive formations within which their clothes choices are made is the old cultural trope of Mutton Dressed as Lamb. References to this recur both in accounts of dress where they do address age, and in the comments of respondents in studies about ageing (Fairhurst 1998, Holland 2004). Mutton dressed as lamb is an oddly old fashioned phrase whose culinary referent is now largely lost, but it is still widely recognised and used as a term of control, policing women's appearance. The action it castigates is dressing in an inappropriately youthful way, but underlying this is the meaning of an inappropriately sexual way. Fairhurst (1998) quotes one respondent in her study evoking the meaning of the phrase:

a lot of excessive jewellery on and very, very heavy make-up and pencil type skirts and slits and big - high, you know, really big high heels. That to me is mutton dressed as lamb. (p262)

The phrase is only applied to women, and is linked to other dangers in the form of looking tarty, like an old slag, or slapper. The references to prostitution underline the essentially sexual nature of the condemnation and the sense that is related to forms of sexuality that are deemed both inappropriate and to some degree threatening to the moral order.

The ambivalences that women feel about dressing down and adjusting their appearance with age are experienced even by those who adopt alternative, countercultural, or 'anti-fashion' styles. Holland's (2004) study of women who adopt alternative appearance - coloured dreadlocks, tattoos, piercings, leather - illustrates the ambivalence felt by this group as they pondered their future ageing. In the section Defying the Crone the respondents reflect on how, and how far, they can combine their 'difference' as alternative women with being middle-aged or elderly. Many recognised with regret, and at times defiance, the pressure on them to tone down their appearance. Being radical and outrageous was part of their self identity. But the prospect of ageing brought new and unwelcome images in this regard, ones of the bag lady, or the mad old witch with her cats. The fear was not one of being outrageous or 
different - this was something they had embraced - but of becoming monstrous or grotesque. The moral judgements imposed on older women who deviate from clothing norms are thus harsher than in earlier years, and contain a negative, objectifying quality that is hard to embrace within a positive form of identity.

To speak of age ordering and its moral enforcement can suggest, however, an overrigid analysis, one in which culture presses down on older people and their bodies, imprisoning them in disciplinary structures, with little in the way of personal autonomy or agency. It also presents a somewhat ahistorical account, in which there is no recognition of changes that might have occurred in the cultural location of older people and the treatment of their bodies. In the following section I want to turn to these issues, exploring how far older people are able to exert agency in relation to dress, and how this relates to questions concerning the tension between age-denial and age-affirmation in terms both of the body and identity. In the last section I will address questions of the changing structural location of older people and its potential implications for self expression and choice in dress. In other words has the nature of ageing altered, so that cultural patterns like age ordering are now less relevant?

\section{Agency and dress: age resistance, age denial}

So far we have spoken of dress as something that is imposed by culture or the fashion or clothing system - a form of social ordering, reinforced by moralistic discourse. But we need to acknowledge the ways in which dress is also an arena for the exercise of agency. That is certainly how it is articulated within the prevailing consumer culture where individuals are encouraged to regard consumption as an expression of identity. Recent empirical work around the experiential aspects of dress has reinforced this interpretation. Guy, Green and Banim (2000) for example argue that we need to refocus our understanding of dress away from the fashion system and its dictates and towards the lived experience of clothes in individual women's lives. Work on consumption has tended to present clothing in terms of the initial point of purchase, but this is to miss the ways in which clothes are consumed and re-consumed over time, how they become 'active' in a wardrobe, are worn in different ways, incorporated into different looks, before being eventually discarded (Guy and Banim 2001). For many women, clothes are an important field for the exercise of agency and expression of identity. 
And yet dress is also clearly the product of forces - social and economic - that are far from individual or particular to the self. The dress of most people reflects very closely the clothing presented to them through the fashion system, so that though individual choices are made, they are done so within a fairly narrow compass. People buy from the same market, and this shapes their choices. The ease with which we can recognise the dates of photographic images demonstrates this process: most people end up looking fairly alike, their appearance strongly reflecting the period and social grouping. Indeed the dream of agency in dress often appears to be closely related to conformity, as we can see in relation to youth styles. Dress is experienced by the young as a significant source of self expression, a genuine focus of agency in their experience of their lives, and yet clothing among the young can exhibit quite extreme levels of conformity in which the presentation of the body is policed at a micro level. Part of the answer to this paradox lies in what Simmel recognised as the central tension in fashion, the conflict between the desire to fit in and to stand out. Fashion for Simmel expresses the tension between the desires for social equalization and for individual differentiation and change, between the convergent and divergent forces of the individual and society (Simmel 1904/1971). Clothes can indeed be expressive of individuality and agency: they do have personal meanings that are distinctive to the individual. But the choice of them and the meanings that attach to them are to large extent determined by the surrounding social, economic and cultural context. The voluntarism of dress can be greatly exaggerated.

What does this mean in relation to older people? We have already seen how the pressure to conform in regard to age applies even to alternative women who consciously flout social norms in relation to dress (Holland 2004). Agency for older people appears therefore to be fairly limited. But is this to miss the possibilities of resistance? Moreover, are moral strictures in relation to dress in the process of changing, so that resistance to ageing discourses is increasingly possible? Is ageing in the context of consumer culture a different experience, one in which there are new possibilities for the exercise of agency? As we shall see shortly, various as sertions are made in this regard; though there are also rival interpretations in the field. Before exploring these questions, we need to touch on debates concerning age-resistance, 
age-denial and the dream of agelessness, for these are relevant to the constraints that older people may face in negotiating new practices in relation to dress.

\section{Age-resistance, age-denial}

One of the ways in which we can examine the intersections between the body, identity and agency is in terms of tensions between strategies of age-resistance and age-denial. Cultural critics like Gullette (1997) and Featherstone and Hepworth (1991) have traced the ways in which culture imposes negative meanings on the bodies of older people which are then read back as the source of those meanings. For Gulette, we are aged, not by our bodies, but by culture; and the response to this should be one of challenge and resistance, as the words Cultural Combat in the title of her book make clear. Featherstone and Hepworth (1991) present a parallel but slightly different interpretation in terms of the Mask of Ageing, in which they point to the discrepancy people experience between the aged face in the mirror and the enduring sense of self. Ageing imposes a false mask over the self, impeding the individual's ability to be and express who they really are. In this way, selfidentity in age is increasingly at odds with bodily experience.

Neither Featherstone and Hepworth nor Gullette deny the existence of bodily ageing, though their work has at times been interpreted as coming near to doing so in the emphasis they put on the cultural constitution of the body. Some have seen a dream of agelessness as implicit in their approaches, in which identity is seen as something quite separate from the body and the processes of age. As a result their work has been subject to critique from those who see it as endorsing a false dualism of the body and the self (Oberg 1996, Biggs 1997, Conway and Hockey 1998, Andrews 1999, Kontos 1999). For Andrews the dream of agelessness though superficially attractive is ultimately erosive since it requires people to deny who and what they are by virtue of having lived the lives that they have. It devalues the ways in which we are our bodies, and how changes in relation to them are part of ourselves. Identity is thus not just the product of a current assertion of choice, as extreme postmodernists suggest, but of a long history (Vincent 1999) in which the experience of bodily ageing is part. Continuity here is not the same as agelessness. Age-resistance is something that comes perilously near age-denial. Such strategies, Andrews argues, are ultimately self 
defeating, not only because the body will inevitably age, but because they involve the internalisation of society's devaluation of older people.

Oblivious to the sources of our strength in old age and to the possibility of self renewal, we blindly create and sustain the conditions of our own self censorship, and ultimately our own defeat.

By this means 'the dignity of the self is replaced by a secret self loathing' (Andrews p307).

We can see some of the ways in which these tensions are played out in clothing choices. Age-resistance here can mean rejecting the cultural denigration implicit in the processes that assign older women drab, frumpy, shapeless and concealing garments - clothing that endorses the cultural norm of invisibility and that acts to entrench the sidelined status of the old. Such strategies, however, contain their own dangers in the form of radical age-denial through the pursuit of youth styles that present the body - and the self - as if it were unchanged, and in doing so only serve to expose and emphasise those changes. By this token, the pursuit of age-denial can lead individuals into strategies that undermine, in Andrew's words, the dignity of self, and frustrate what Fairhurst (1998) reports as the widely endorsed aim of growing old gracefully.

Part of the difficulty in assessing such strategies comes from the way in which resistance is itself a profoundly ambiguous term. This holds true both of its Foucauldian origins, where the foundation of resistance remains untheorised - its existence asserted but its sources opaque - and its use more generally within sociology, where problems recurringly arise in relation to what can properly be regarded as resistance. In the field of ageing and dress, is the exaggerated fluffy pink femininity of Barbara Cartland noted by Holland (2004) resistance to the cultural demand to tone down and retreat from female sexuality, or exaggerated conformity to the discourses of conventional femininity? As Furman (1999) notes in her classic account of the beauty shop and age, what counts as resistance and what capitulation is far from clear, so that ambiguity is piled on ambiguity. In this way, postmodern analyses often end up exposing as many problems as they seek to resolve. There is no simple answer to the tension between age resistance and age denial. 


\section{Consumer culture: the challenge to, or entrenchment of, age ordering?}

This finally brings me to debates about consumption and its role in the reconstitution of old age. We noted earlier the powerful tradition of age ordering in dress. Has the old pattern of age ordering given way to new fluidity in the face of consumer culture? Or has it reasserted itself in more subtle forms? The emergence of the Third Age as a new cultural space - itself the product of a series of social and cultural shifts: the growing proportion of older people in the population, greater longevity after retirement and improved health, and increased material and cultural resources - has, cultural critics argue, disrupted the old narrative of age in terms of marginalisation and decline. The institutional structures that once maintained the life cycle have been destabilised, disembedding individuals from earlier sources of identity, presenting them with new opportunities for choice and self-ascription in the market. For Gilleard and Higgs (2005), there is in addition a cohort effect, arising from the maturation of a generation that pioneered youth culture and its subsequent development into consumer culture so that their attainment of Third Age status marks a new stage in the cultural constitution of age. These elders have no wish to forgo the pleasures of consumption - no desire or intention to adopt 'older' styles or modes of life. Their wish is to remain part of mainstream consumer culture. Age ordering from their perspective is oppressive, something to be resisted.

This interpretation in terms of growing fluidity and choice certainly fits with the widely held perception that the dress of people in middle and later years is no longer constrained by cultural norms as it once was. The old hierarchies in relation to age and dress appear to have broken down, together with the institutional structures that previously entrenched the normative life cycle, with the result that the age ordering that was a prominent feature of the dress of older people in previous generations has gone. This is certainly how the clothing industry itself, conscious of the economic power of this group (Sawchuk 1995, Long 1998), presents the situation. From the official perspective of retailers and advertisers, there are no clothes for older people as such, just a variety of modes aimed at different lifestyles, in which customers are free to choose as they wish.

Not all analysts, however, endorse this view; and Crane (2000), writing from the perspective of a theorist of dress rather than a social gerontologist has advanced a 
radically different interpretation. She argues that age in relation to dress, rather than reducing in significance, has increased, replacing the previously dominant role of social class. Sociologists from the days of Veblen (1890/1953) and Simmel (1904/1971) have accorded a primary role to social class in the explanation of fashion, tracing the shift from feudally-ordered societies in which distinctive clothes are used to mark social categories and enforced by means of sumptuary legislation, towards class-based societies in which competitive emulation and the pursuit of class-based distinction fuel the engine of fashion. The emergence of class society is thus linked to changes in the clothing system, as dress becomes a tool in the battle for social status, part of the dynamic of competitive emulation and display in which styles are diffused downwards from social elites. By these means the upper classes attempt constantly to display their distinction through separating themselves off from lower orders.

Crane (2000), however, argues that from the late-twentieth century this dynamic of class no longer has the primacy that it once did; the engine of fashion has shifted to age.

Instead of the upper class seeking to differentiate itself from other social classes, the young seek to differentiate themselves from the middle aged and the elderly. As trends diffuse to older age groups, younger age groups adopt new styles (p198).

Such a perception certainly fits with features of the clothing retail market, which has since the 1980s become increasingly differentiated, with the result that mainstream high street staples that could once trade across the age range find it increasingly difficult to do so. The clothing market has become fragmented and differentiated; and in this, age operates as a hidden, unacknowledged variable. Far from disappearing, age ordering may have been transformed into more subtle form as a new dynamic of change.

\section{Conclusion}

One of the most significant developments in social gerontology in the last decade has been the emergence of the cultural dimension in the analysis of age. We have moved from an approach dominated by public policy and social welfare concerns, and implicitly structured by medical discourses, to one that recognises how age and ageing need to be set within the cultural context that constitutes as well as frames it. 
In this article I have argued that clothing presents a particularly apt subject for such new approaches, standing as it does at the interface between the body and the social world, the forces of individual agency and choice and those of collective culture. As such it encapsulates a number of key debates in relation to the body, identity and agency.

As we have seen clothes are one of the principal means whereby we present and see the body, so that how dress operates in relation to age is significant for our understanding of how cultural expectations act at a directly bodily level. Clothing choices in old age, however, also reflect changes in the body, and dress thus offers a field in which we can explore of the complex interplay between the physiological and the cultural in the constitution of old age.

Clothing has also traditionally been embedded age ordering. As we have seen, this is an elusive phenomenon. The retail industry is certainly reluctant to refer to it, and many older people repudiate its influence. And yet there is evidence for the persistence of this cultural form; and we have traced the features that mark it out. Some in relation to cut and - perhaps -colour can be seen as responses to changes in the body; however, their predominant meanings relate to cultural estimations of the status of older people. Pale, drab colours, loose shapeless forms underwrite invisibility and point to social marginalisation. Not all clothing worn by older people is of this type, and we have also noted the widespread adoption of relaxed, easy forms of dress that act to maintain older people within mainstream culture through the imagery of sport; though such forms of dress also contain messages about asexuality and second childishness.

Clothing also exposes some of the disciplinary discourses act upon the lives of older people. As we have noted, these discourses operate in distinctive - frequently moralistic - ways in relation to older people, with the condemnation of inappropriate dress falling particularly heavily on older women in relation to inappropriate sexual display. The moral perils of old age, however, apply not just to sexuality but dereliction, and older people can find themselves judged with a new harshness in relation to lapses of dress, which come to signal an incapacity to maintain the body in a socially acceptable manner, threatening wider social exclusion. 
Such an account in terms of age ordering and the impress of cultural forms has, however, been subject to critique from those who argue that it imposes too rigid an analysis, in which culture is treated as fixed and predetermined, bearing down on individuals, enforcing its meanings, disciplining their bodies. And we have seen how clothes are also an arena for the expression of agency and choice, and how this dynamic opens up possibilities of resistance and change. But as we noted in relation to the body itself, questions of resistance are far from straightforward. There are layers of ambiguity here, in which it is often hard to distinguish between strategies of age resistance and age denial. Whatever postmodern critics may claim, identities cannot wholly float free from bodily experience, nor are they unconstrained by cultural ascriptions. It may be the case, however, that the cultural location of older people is itself changing. Exponents of the Third Age certainly argue that consumer cultural has opened up new opportunities for resistance to traditional discourses of age, integrating older people into the mainstream. But as we have noted, there are reasons to be sceptical of this analysis in relation to clothes. Cultural forms are themselves protean. The nature of the fashion/clothing system may itself be shifting, with age replacing class as the primary engine of change. Far from integrating older people into the mainstream, consumer culture may be imposing a new and more subtle forms of age ordering.

\section{References}

Andersson, L. (ed) (2002) Cultural Gerontology, Westport: Auburn House

Andrews, M (1999) 'The seductiveness of agelessness', Ageing and Society, 19, 30118

Bendelow, G. (1993) 'Pain perceptions, gender and emotion', Sociology of Health and Illness, 15, 3, 273-94

Biggs, S (1997) “"Choosing not to be old?” Masks, bodies and identity management in later life' Ageing and Society, 17, 553-70

Breward, C. (2000) 'Cultures, identities, histories: fashioning a cultural approach to dress', in N.White and I.Griffiths (eds) The Fashion Business: Theory, Practice, Image, Oxford: Berg 
Bury, M. (1982) Chronic illness as biographical disruption', Sociology of Health and Illness, 4, 2, 167-82

Bury, M. (1991) 'The sociology of chronic illness: a review of research and prospects', Sociology of Health and Illness, 13, 4, 451-68

Butler, J.P. (1990) Gender Trouble: Feminism and the Subversion of Identity, London: Routledge:

Butler, J. P. (1993) Bodies that Matter: On the Discursive Limits of "Sex"', London, Routledge.

Cole, T. C. (1992) The Journey of Life: A Cultural History of Aging in America, Cambridge: Cambridge University Press

Conway, S. and Hockey, J. (1998) 'Resisting the "mask" of old age: the social meaning of lay health beliefs in later life,' Ageing \& Society, 18, 469-94

Craik, J. (1994) The Face of Fashion: Cultural Studies in Fashion, London: Routledge

Crane, D. (2000) Fashion and Its Social Agendas: Class, Gender and Identity in Clothing, Chicago: University of Chicago Press

Crossley, N. (2001) The Social Body: Habit, Identity and Desire, London: Sage

Daly, M. (1979) Gyn-ecology: the Metaethics of Radical Feminism, London: Women's Press

Dumas, A., Laberge, S. and Straka, S.M. (2005) 'Older women's relations to bodily appearance: the embodiment of social and biological conditions of existence', Ageing \& Society, 25, 883-902

Entwhistle, J. (2000a) The Fashioned Body: Fashion, Dress and Modern Social Theory, Cambridge: Polity

Evans, C. (2003) Fashion at the Edge, New Haven: Yale University Press

Fairhurst, E. (1998) "'Growing old gracefully" as opposed to "mutton dressed as lamb": the social construction of recognising older women' in S. Nettleton and J.Watson (eds) The Body in Everyday Life, London: Routledge

Featherstone, M. and Hepworth, M (1991) 'The mask of ageing and the postmodern life course' in M. Featherstone, M. Hepworth and B. S. Turner (eds) The Body: Social Process and Cultural Theory, London, Sage.

Fine, B. and Leopold, E (1993) The World of Consumption, London: Routledge Flugel, J. C. (1930) The Psychology of Clothes, London: Hogarth Press

Friedan, B. (1963) The Feminine Mystique, London: Gollanz 
Furman, F.K. (1997) Facing the Mirror: Older Women and Beauty Shop Culture, New York: Routledge

Gilleard, C. and Higgs, P. (2000) Culture of Ageing: Self, Citizen and the Body, London: Prentice Hall

Gilleard, C. and Higgs, P. (2005) Contexts of Ageing: Class, Cohort and Community, Cambridge: Polity

Goldsberry, E., Shim, S., Reich, N., (1996) 'Women 55years and older: Part I Current body measurements as contrasted to the PS 42-70 data' Clothing and Textiles Research Journal, 14, 2, 108-120

Greer, G. (1971) The Female Eunuch, London: Paladin

Gullette, M. M. (1997) Declining to Decline: Cultural Combat and the Politics of Midlife, Charlottesville: University Press of Virginia

Gullette, M.M. (1999) 'The other end of the fashion cycle: practising loss, learning decline' in K.Woodward (ed) Figuring Age: Women, Bodies, Generations, Bloomingdale: Indiana University Press

Guy, A., and Banim, M.(2000) ‘Personal collections: women's clothing use and identity', Journal of Gender Studies, 9, 3

Guy, A., Green, E. and Banim, M.(2001) 'Introduction', in A.Guy, E.Green and M.Banim (eds) Through the Wardrobe: Women's Relationship with Their Clothes, Oxford: Berg

Harvey, J. (1995) Men in Black, London; Reaktion Books

Holland, S. (2004) Alternative Femininities: Body, Age and Identity, Oxford: Berg

Hollander, A. (1978) Seeing Through Clothes, Berkeley: University of California Press

Holliday, R. (2001) 'Fashioning the queer self' in J. Entwhistle and E. Wilson (eds) Body Dressing, Oxford: Berg

Iltanen, S. (2005) 'Constructing the image of a user through design', paper delivered at British Society for Gerontology Conference, University of Keele

Jeffries, S. (2005) Beauty and Misogyny: Harmful Cultural Practices in the West, London: Routledge

Katz, S. (1996) Disciplining Old Age: The Formation of Gerontological Knowledge. Charlottesville, University Press of Virginia

Katz, S. (2005) Cultural Aging: Life Course, Lifestyle and Senior Worlds, Peterborough, Ontario: Broadview Press 
Khan, N. (1993) 'Asian women's dress: from burqah to bloggs' in in J.Ash and E.Wilson (eds) Chic Thrills, Berkeley: University of California Press

Kontos, P.C. (1999) 'Local biology: bodies of difference in ageing studies,' Ageing and Society, 19, 6, 677-89

Lawton, J. (2003) 'Lay experiences of health and illness: past research and future agendas' Sociology of Health and Illness, 1, 3-23

Leder, D. (1990) The Absent Body, Chicago: University of Chicago Press

Long, N. (1998) 'Broken down by age and sex - exploring the ways we approach the elderly consumer', Journal of Market Research Society, 40, 2, 73-92

Lurie, A. (1992) The Language of Clothes, London: Bloomsbury

MacDonald, M.F., Galassi, S.G., Ribeiro, A. (2003) Whistler, Women and Fashion, New Haven: Yale

Merleau Ponty, M (1962) The Phenomenology of Perception, London: Routledge Kegan Paul

Oberg, P. (1996) 'The absent body - a social gerontological paradox', Ageing and Society, 16, 6, 701-19.

Polhemus, T. (1994) Streetstyle: From Sidewalk to Catwalk, London: Thames and Hudson

Ribeiro, A. (1995) 'Truth and history: the meaning of dress in art' in A. Ribeiro (ed) The Art of Dress: Fashion in England and France 1750-1820, New Haven: Yale

Ribeiro, A. (2002) Dress in Eighteenth Century Europe, New Haven: Yale

Ribeiro, A. (2005) Fashion and Fiction: Dress in Art and Literature in Stuart England, New Haven: Yale

Rolley, K. (1993) 'Love desire and the pursuit of the whole: dress and the lesbian couple' in J.Ash and E.Wilson (eds) Chic Thrills, Berkeley: University of California Press

Sawchuk, K. A. (1995) 'From gloom to boom: age, identity and target marketing' in M. Featherstone and A. Wernick (eds) Images of Aging: Cultural Representations of Later Life, London: Routledge

Shilling, C. (1993) The Body and Social Theory, London: Sage

Shilling, C. (2005) The Body in Culture, Technology and Society, London: Sage Simmel, G (1904/ 1971) 'Fashion', On Individuality and Social Forms: Selected Writings, trs D.C.Levine, Chicago: University of Chicago Press 
Smathers, D.G. and Horridge, P.E. (1978) 'The effects of physical changes on clothing choices of elderly women', International Journal of Aging and Human Development, 9, 3, 273-8.

Steele, V. (1997) Fifty Years of Fashion: New Look to Now, New Haven: Yale University Press

Tulle-Winton, E. (1999) 'Growing old and resistance: the new cultural economy of old age?' Ageing and Society, 19, 281-299

Tulle-Winton, E. (2000) 'Old bodies' in P.Hancock, B. Hughes, E.Jagger, K.Paterson, R.Russell, E.Tulle-Winton and M.Tyler (eds) The Body, Culture and Society, Buckingham: Open University

Tseelon, E. (1995) The Masque of Femininity, London: Sage

Tseelon, E. (2001) 'Ontological, epistemological and methodological clarifications in fashion research: from critique to empirical suggestions' in A.Guy, E.Green and M.Banim (eds) Through the Wardrobe: Women's Relationship with Their Clothes, Oxford: Berg

Twigg, J. (2004) 'The body, gender and age: feminist insights in social gerontology' Journal of Aging Studies, 18, 59-73

Vincent, J. (1999) 'Consumers, identity and old age', Education and Ageing, 14, 2, $141-58$

Wahadin, A. (2002) 'Reconfiguring older bodies in the prison time machine' Journal of Aging and Identity, 7, 3, 177-93

Williams, S.J. (1999) 'Is anybody there? Critical realism, chronic illness and the disability debate', Sociology of Health and Illness, 21, 6, 797-819

Wilson, E. (1985) Adorned in Dreams: Fashion and Modernity, London: Virago

Woodward, K. (ed) (1999) Figuring Age: Women, Bodies, Generations, Bloomington: Indiana 